\title{
RESEÑA
}

\section{Cosechando Justicia: Café de Comercio Justo, Sustentabilidad y Sobrevivencia de Daniel Jaffee}

\author{
Sergio Gabriel Ceballos Pérez, Catedrático Conacyt sergiocbpz@gmail.com \\ ORCID: https://orcid.org/0000-0003-4991-3540 \\ DOI https://doi.org/10.47386/2020V1N3E2
}

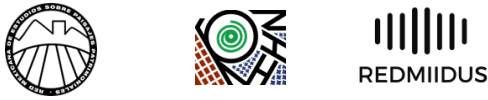

Este libro es la reedición en español del libro Brewing Justice gran cantidad de intermediarios, ofreciendo productos elaboeditado por University California Press del autor Daniel Jaffee rados con técnicas más tradicionales, así como ecológicamente quien es profesor titular del Departamento de Sociología en la más sustentables. Por otro lado, como segundo objetivo geneUniversidad Estatal Portland en Oregón, Estados Unidos. rar conciencia en los consumidores de dónde provienen los Quien a lo largo de sus poco más de cuatrocientas páginas nos productos que consumen, y quienes los producen. adentra al complejo mundo del comercio justo, un tema controversial para todo tipo de público, pero que bien refleja la necesidad, desequilibrios y externalidades negativas del comercio masivo, la globalización y la competencia desleal, amparados bajo los tratados internacionales.

Los compradores de productos de comercio justo son en su mayoría personas consientes de la realidad de los pequeños productores. Un ejemplo de ello, son los productores de café, que de hecho fue el primer producto en entrar al comercio justo. La historia de los productores de café en los países subLa introducción y el prefacio, abren desatando el interés del desarrollados ha sido contrastante, la mayoría de ellos, por lo lector con los acontecimientos internacionales de la baja de precios de productos como el maíz, el café, plátano, etc., los cuales son solo algunos de los productos que sufren de una caída histórica debido a la producción comercial, afectando a los productores de los países del sur global, término acuñado para referirse hoy a los países subdesarrollados.

Uno de los problemas del empobrecimiento del sector rural, en particular de los países subdesarrollados se debe a las escasas o nulas ganancias que obtienen de sus productos, la mayor parte de estas la obtienen los comercializadores e industrias de los productos primarios, dejando así un campo descapitalizado y productores pobres que tienen que abandonar el campo y vender sus tierras.

Por otro lado, los países industrializados subsidian a sus productores agrícolas generando así un comercio todavía más injusto. Al lado, de esto grandes industrias que trabajan mediante la agricultura por contrato, dañan los ecosistemas, y de la misma manera, el productor tiene que acatar al pie de la letra las normas del contratista, para que su producción sea adquirida al final de la cosecha.

El comercio justo nació como una propuesta de los mismos productores de llegar a los mercados sin necesidad de una nadas o de difícil acceso, con niveles de pobreza muy altos. La producción de los cafetales se da en zonas de altura que combinan ecosistemas como selvas, bosques de neblina, bosques húmedos, entre otros. Ahí las pequeñas familias que dependen de la producción de maíz y frijol, dedican una parte de sus tierras para producir café y así tener un poco más de ingresos.

El libro que consta de 10 capítulos hace una explicación profunda y con una redacción muy accesible para cualquier lector, analizando el comercio justo en una pequeña localidad de productores de café pertenecientes a Yagavila, una comunidad perteneciente a la Sierra Norte de Oaxaca, y en la cual el autor estuvo investigando y viviendo para conocer la experiencia en carne propia de los productores. Con ello, pone sobre la mesa la discusión sobre el comercio justo, pensando no en un modelo económico sino como un movimiento social y político. Se discuten aspectos importantes tales cómo las debilidades del mercado justo, las cuales requieren de una amplia participación social e innovar en los nichos de mercado cada vez más competidos.

El comercio justo de acuerdo con el autor es también una forma de rebeldía y protesta ante el sistema esclavizante y opre- 
sor, sistema que deja fuera a los más pobres o los mantiene agrupan tienen un poco más de ventajas que aquellos que no. oprimidos con bajos ingresos y cerrándoles el camino hacia los mercados. Los pequeños productores de café están expuestos a diversos peligros y abusos por parte de los mayoristas, de las autoridades que lejos de apoyarlos buscan obtener algún beneficio en el corto plazo. De esas prácticas son las que buscan librarse, llegar a los consumidores finales lo más cercano posible y que los beneficios del café se vean también sus comunidades y familias.

Por último, otro tema interesante que toca el libro es la suficiencia alimentaria y la migración, para las comunidades el café representó desde hace años un tipo de moneda, en la actualidad, ellos guardan café para poder intercambiarlo por dinero en caso de emergencias. No obstante, debido a los bajos precios internacionales de café, ese dinero cada vez es menos, por ende, aquellos que se arriesgan a producir sólo café les puede salir contraproducente al no tener para adquiPor otra parte, el comercio justo está adentrándose en las rir alimentos. Si uno conociera todas estas y más razones, grandes compañías como Nestlé, Starbucks, Walmart, entre definitivamente uno elegiría un café de comercio justo de otras, que pagan de forma directa a los productores, aunque entre un café comercial.

sea en un porcentaje bajo de sus proveedores, pero hay una mayor conciencia del efecto que tiene una gran empresa de esa naturaleza en la fijación de los precios y en la exclusión versus integración de las comunidades.

La lectura de este libro, además de una buena prosa y narrativa de los paisajes y los actores sociales, se antoja junto a una taza de café, lleno de historias y realidades que no imaginamos, de los procesos y crisis que enfrentan los productores y El café sustentable, de acuerdo con el autor podría ser un café de la realidad que existe dentro de cada taza de café que beorgánico o una plantación de café en sistemas agroecológicos, bemos. El libro además cuenta con opción a descargarse de sin embargo, esto no es posible para las plantaciones comer- manera electrónica en forma gratuita, por lo que los invitaciales, los pequeños productores son los únicos en poder rea- mos ampliamente a leerlo.

lizarlos, y para entenderlo, se requiere una conocer de forma más profunda cómo funciona la producción de café. Como se comenta en el libro, la producción de café requiere atención, pero también un delicado equilibrio entre otros cultivos, que puede ser maíz y frijol, o incluso otros cultivos de sombra, ya que si se planta sólo café las plagas como la roya pueden atacar los cultivos y se tendrán que usar pesticidas, terminando así en productos con agroquímicos. En ese sentido la producción sustentable de café sólo se puede llevar a cabo en las zonas serranas dónde la mayoría de las comunidades indígenas de México habitan y que son quienes conocen este tipo de sistemas de producción.

La sustentabilidad por su parte, también conlleva a buscar que las comunidades se vean beneficiadas con la venta de su café a un buen precio, fruto de su trabajo y la tierra que deben cuidar para que se mantenga. En ese sentido, la organización en uniones o grupos de productores también es un tema interesante, y a su vez complejo que aborda el libro. La unión de productores conlleva compromisos y responsabilidades, inversiones, que no todos tienen ya sea económica, temporal o físicamente la capacidad de asumir. No obstante, quienes se 